\title{
LIPOMA PAROSTEAL DE ARCO COSTAL: RELATO DE CASO*
}

\author{
Celso Montenegro Turtelli ${ }^{1}$, Pedro Paulo Saad Costa ${ }^{2}$, Helder de Souza Lima e Silva ${ }^{2}$
}

Resumo Os autores relatam o caso de um paciente com história de tumoração na região subaxilar esquerda, de crescimento progressivo, com início há vários anos. A radiografia e a tomografia computadorizada evidenciaram lesão expansiva com densidade menor do que partes moles adjacentes, com contornos bem definidos, contígua ao quinto arco costal esquerdo, com ossificações irregulares em seu interior. Histologicamente, foi diagnosticado lipoma parosteal, um raro tumor benigno de crescimento lento.

Unitermos: Lipoma parosteal; Costela; Tumor de tecidos moles.

Abstract Parosteal lipoma of the rib: a case report.

The authors report a case of a patient with a progressive-growing mass in the left subaxillary region, since childhood. Chest $\mathrm{x}$-ray and computed tomography showed a well-defined low attenuation mass with irregular calcifications contiguous with the left fifth rib. Histological findings were consistent with parosteal lipoma, a rare slow-growing benign tumor.

Key words: Parosteal lipoma; Rib; Soft tissue tumor.

\section{INTRODUÇÃO}

Lipomas são as neoplasias mais comuns dos tecidos moles. São raros nas duas primeiras décadas de vida, aparecendo usualmente quando o tecido adiposo começa a se acumular.

Segundo Enzinger e Weiss há dois tipos de lipomas isolados: superficiais (freqüentemente encontrados no tecido subcutâneo dos ombros, costas, pescoço e abdome) e profundos (mais comuns no mediastino anterior, parede torácica e retroperitônio), sendo estes últimos mais $\operatorname{raros}^{(\mathbf{1})}$.

O lipoma parosteal é um tipo de lipoma profundo que cresce exofiticamente ao periósteo, podendo causar erosão óssea, compressão neural ou hiperostose cortical focal. Trata-se de um tumor raro, histologicamente benigno, de crescimento lento, que compreende $0,3 \%$ de todos os lipomas. Na maioria dos pacientes é diagnosticado por volta dos 40 anos de idade e ocorre mais freqüentemente no sexo masculino, numa proporção de 1,6:1. Desenvolve-se geralmente na superfície diafisá-

* Trabalho realizado na Disciplina de Radiologia e Diagnóstico por Imagem da Faculdade de Medicina do Triângulo Mineiro (FMTM), Uberaba, MG.

1. Professor Adjunto de Radiologia da FMTM, Chefe do Serviço de Radiologia do Hospital São Domingos.

2. Residentes de Radiologia da FMTM.

Endereço para correspondência: Prof. Dr. Celso Montenegro Turtelli. Rua Constituição, 751. Uberaba, MG, 38025-110. E-mail: celsomt@mednet.com.br

Recebido para publicação em 24/6/2004. Aceito, após revisão, em 28/9/2004. ria de ossos longos, especialmente fêmur, rádio proximal, úmero e tíbia ${ }^{(1,2)}$.

O envolvimento da costela é muito raro. Imbriaco et al. $^{(3)}$ relataram um caso, que conforme revisão, foi o segundo caso descrito na literatura ${ }^{(3,4)}$.

\section{RELATO DO CASO}

Paciente do sexo masculino, 48 anos de idade, com história de tumoração mole na região subaxilar esquerda há vários anos. Relatava ter procurado serviços facultativos anteriormente, sem resolução do caso. Notou que há mais ou menos oito anos a tumoração vinha crescendo lenta e progressivamente, tornando-se mais endurecida. Não havia queixas relacionadas a outros sistemas.

Ao exame físico evidenciou-se tumoração subaxilar esquerda, indolor, fixa, dura, medindo aproximadamente $15 \mathrm{~cm}$. A radiografia simples de tórax evidenciou lesão expansiva adjacente ao quinto arco costal esquerdo lateralmente, de contornos bem definidos, com áreas de ossificações em seu interior (Figura 1).

A tomografia computadorizada de tórax demonstrou lesão expansiva com coeficiente de atenuação de -114 unidades Hounsfield, compatível com tecido adiposo (Figura 2). Com janela óssea, a tomografia computadorizada evidenciou áreas de ossificações irregulares arborescentes (Figura 3).

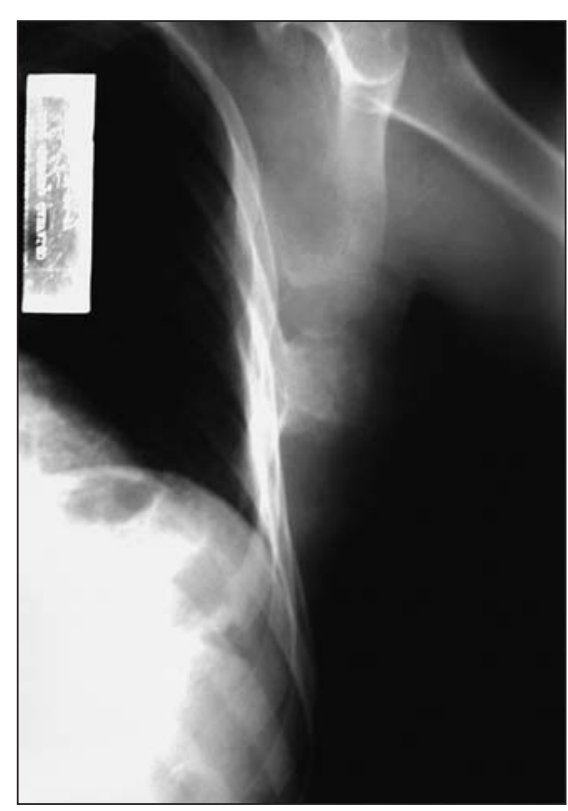

Figura 1. A radiografia localizada do hemitórax esquerdo mostra lesão expansiva radioluscente, de contornos regulares, contendo áreas de ossificações irregulares projetando-se do periósteo.

Foi realizada excisão cirúrgica da massa, com costectomia. O produto de ressecção cirúrgica em bloco compreendeu a massa tumoral com segmento do quinto arco costal. Na face externa da costela notava-se neoformação de osso esponjoso com superfície de corte avermelhada e com porção periférica branca e muito delgada. A neoformação óssea distava $4 \mathrm{~cm}$ da extremidade do arco costal e era circundada parcialmente por tecido adiposo medindo 


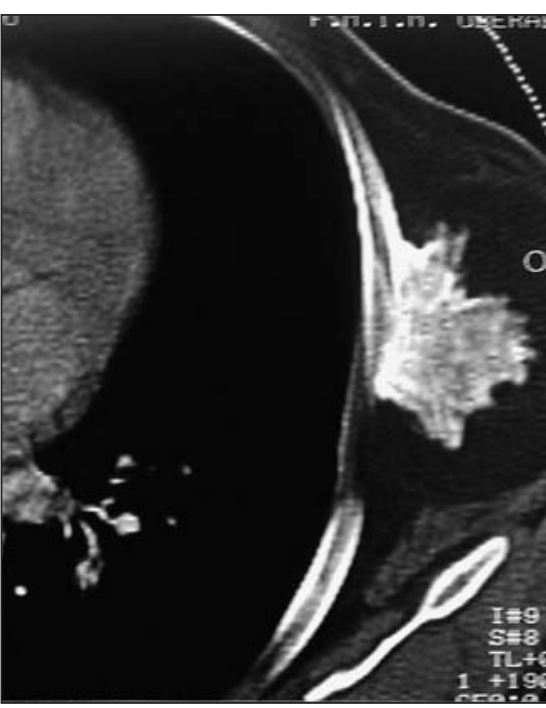

Figura 2. Tomografia computadorizada mostra massa de tecido mole com coeficiente de atenuação de -114 unidades Hounsfield (compatível com tecido adiposo).

2,5 $\mathrm{cm}$ de espessura. O limite entre ambos era nítido, porém irregular. O resultado do exame anatomopatológico confirmou o diagnóstico de lipoma parosteal da costela. O paciente não apresentou recorrência no pós-operatório.

\section{DISCUSSÃO}

Lipomas são neoplasias comuns e benignas de tecido adiposo. Ocorrem freqüentemente nos ombros, nas costas e no pescoço $^{(\mathbf{1})}$. Quando crescem em contato com ossos, são denominados lipomas parosteais. Tais lesões são infreqüentes e respondem por apenas $0,3 \%$ de todos os lipomas $^{(5)}$.

Prefere-se a terminologia lipoma parosteal em vez de periosteal, uma vez que adipócitos não são encontrados no periósteo normalmente ${ }^{(6)}$.

Caracteristicamente, apresentam-se como massa fixa, de crescimento lento, de grandes dimensões e não fixada à pele ${ }^{(7)}$. Macroscopicamente, têm formas variadas, são amareladas e amolecidas, tendendo a ser bem delimitados dos tecidos adjacentes por fina cápsula fibrosa. Atingem geralmente 4 a $10 \mathrm{~cm}$ em suas maiores dimensões. Microscopicamente, diferem muito pouco do tecido adiposo normal, consistindo de lóbulos de adipócitos brancos maduros. São bem vascularizados, porém

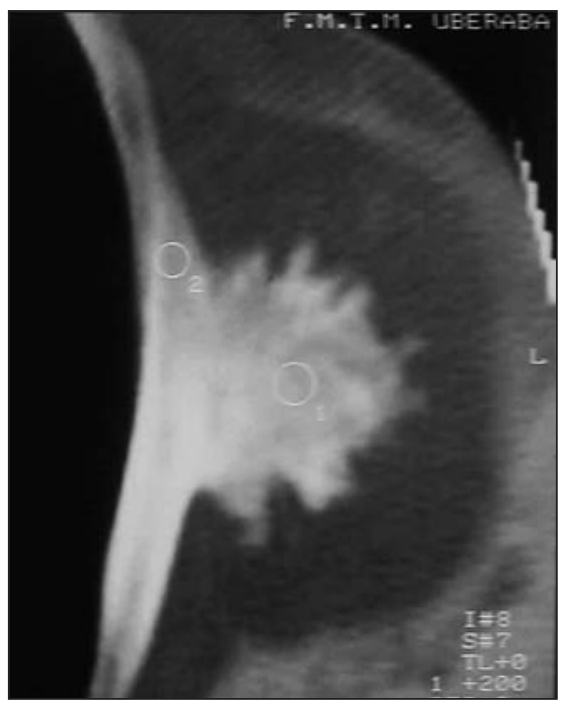

Figura 3. Tomografia computadorizada revela áreas de ossificações irregulares arborescentes no interior da lesão.

os vasos não são distinguíveis devido à compressão pelas células adiposas. $\mathrm{O}$ adipócito apresenta um único e grande vacúolo citoplasmático, que desvia os núcleos perifericamente. Alguns casos apresentam ossificações com cartilagem hialina na base da lesão ou difusas pelo tumor em pequenas "ilhas"(1,2) (Figura 4). Estas ilhas são atribuídas a metaplasia de células mesenquimais pré-existentes ${ }^{(\mathbf{8})}$.

Podem ser grandes suficientemente para causar limitação do movimento de uma articulação ou comprimir estruturas como artéria, nervo ou vasos linfáticos. O tratamento de escolha é a excisão cirúrgica ${ }^{(3)}$.

Radiologicamente, observa-se área hipertransparente bem definida aderida à cortical externa óssea, podendo ocorrer ilhas de calcificações ou ossificações em seu interior ${ }^{(9)}$. A tomografia computadorizada geralmente revela massa de densidade idêntica ao tecido adiposo, com excrescências ósseas projetando-se do periósteo do osso adjacente, podendo ocorrer erosão deste $^{(3,10)}$. A ressonância magnética, quando realizada, mostra massa de tecido mole hiperintensa em imagens ponderadas em $\mathrm{T} 1$ e $\mathrm{T} 2^{(\mathbf{1 0})}$. A tomografia computadorizada e a ressonância magnética são úteis em confirmar a natureza não agressiva desta lesão, mostrando a relação da massa com o osso adjacente e excluindo um processo maligno $^{(3)}$. (O lipossarcoma costuma ser mal-definido e heterogêneo, podendo invadir estruturas adjacentes com possível metástase a distância ${ }^{(\mathbf{1 1})}$ ).

O diagnóstico diferencial deve ser feito com osteoma parosteal, osteossarcoma parosteal, osteoblastoma periosteal, miosite ossificante e melorreostose $^{(\mathbf{1 2})}$ (Figura 5).

\section{REFERÊNCIAS}

1. Enzinger FM, Weiss SW. Benign lipomatous tumors. In: Enzinger FM, Weiss SW, eds. Soft tissue tumors. 3rd ed. St. Louis: Mosby,1995:381-430.

2. Fletcher CDM, Unni K, Mertens K. WHO Classification of tumours. Pathology and genetics of tumours of soft tissue and bone. Lyon: IARC Press, 2002.

3. Imbriaco M, Ignarra R, De Rosa N, Lambiase G,

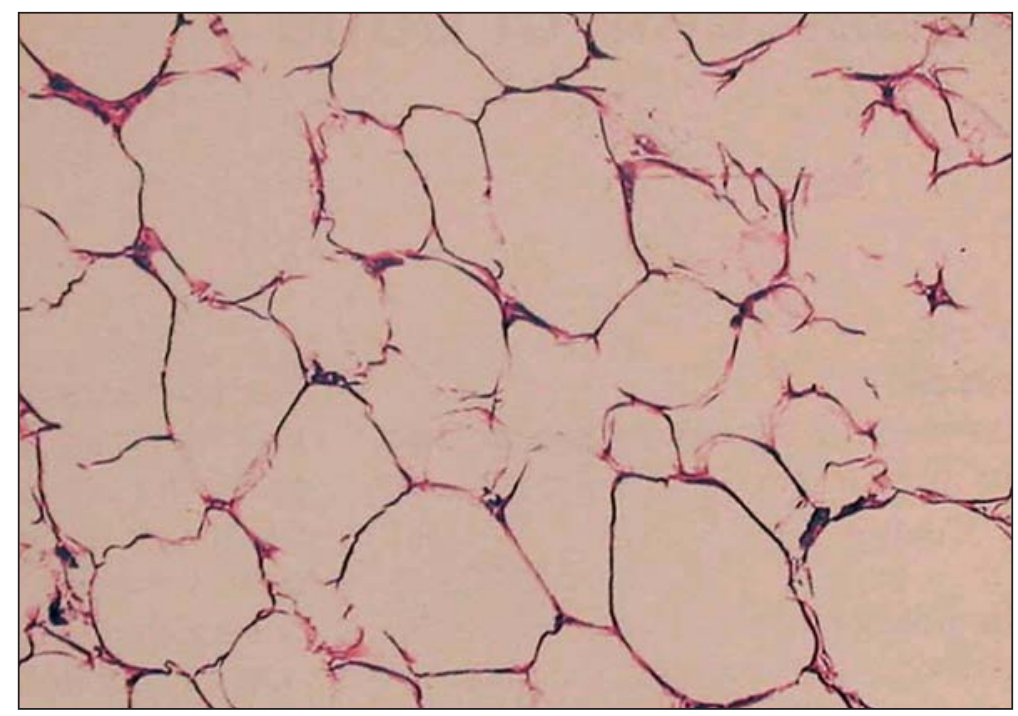

Figura 4. Aspecto microscópico do lipoma parosteal, composto de lóbulos de adipócitos brancos madu$\operatorname{ros}^{(2)}$. 


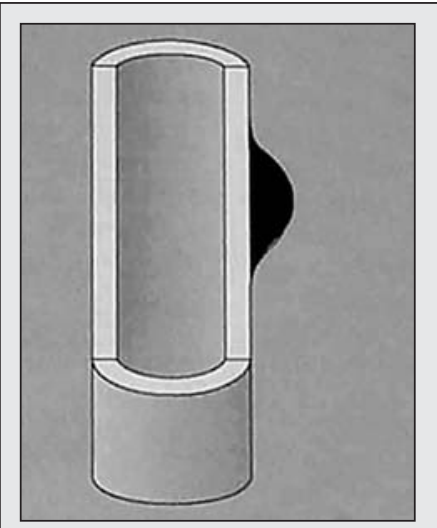

Osteoma

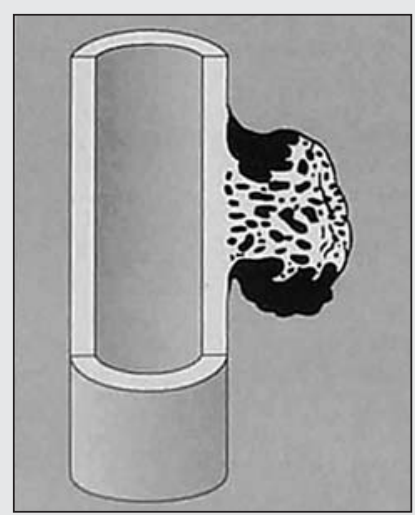

Osteossarcoma parosteal

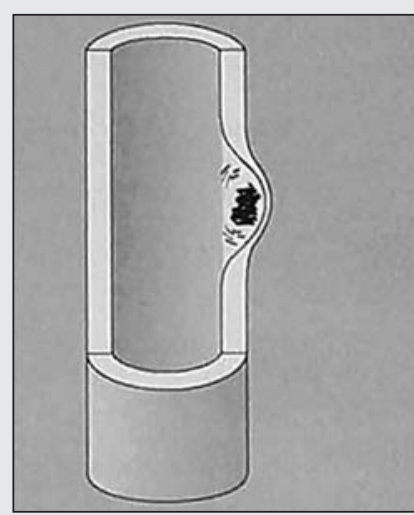

Osteocondroma séssil

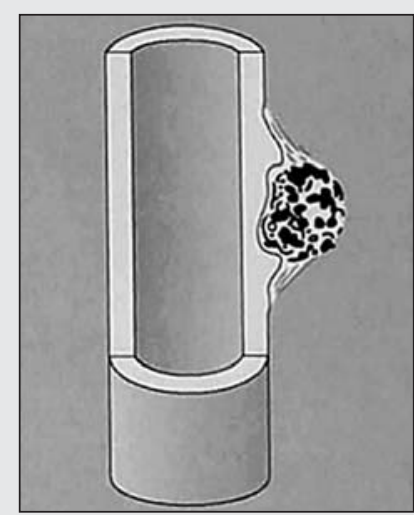

Osteoblastoma periosteal

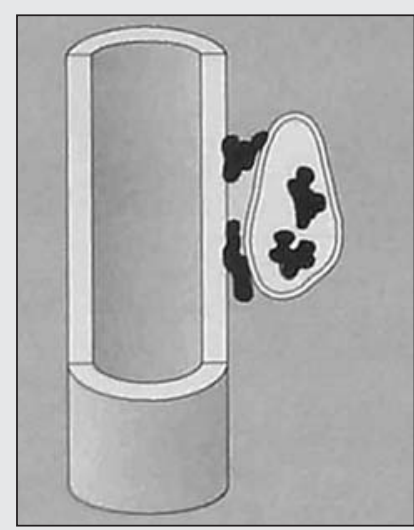

Lipoma parosteal ossificado

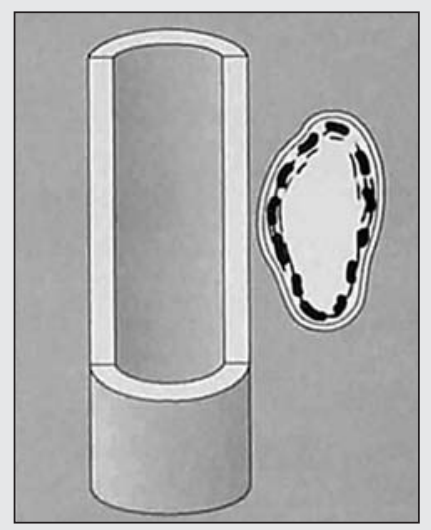

Miosite ossificante

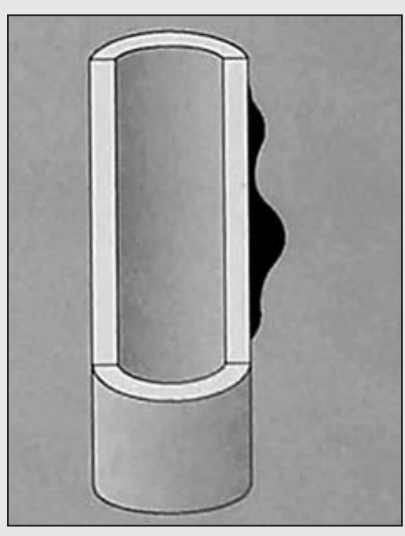

Melorreostose

Figura 5. Diagnóstico diferencial de lesões corticais e justacorticais ${ }^{(\mathbf{1 2})}$.

Romano M, Ragozzino A. Parosteal lipoma of the rib: CT findings and pathologic correlation. Clin Imaging 2003;27:435-7.

4. Fiorentino L, Rossi G, Ruggiero C, et al. Parosteal rib lipoma: description of a case. Pathologica 2001; 93:668-71.

5. Bui-Mansfield LT, Myers CP, Chew FS. Parosteal lipoma of the fibula. AJR 2000;174:1986.

6. Fleming RJ, Alpert M, Garcia A. Parosteal lipoma. AJR 1962;87:1075-84.
7. Kim JY, Jung SL, Park YH, Park SH, Kang YK. Parosteal lipoma with hyperostosis. Eur Radiol 1999;9:1810-2.

8. Miller MD, Ragsdale BD, Sweet DE. Parosteal lipomas: a new perspective. Pathology 1992;24: 132-9.

9. Demos TC, Bruno E, Armin A, Dobozi WR. Parosteal lipoma with enlarging osteochondroma. AJR 1984;143:365-6.

10. Yamamoto T, Marui T, Mizuno K. Parosteal lipoma of the distal phalanx: a case report and review of the literature. Clin Orthop Relat Res 2001;(389):1814.

11. Munk PL, Lee MJ, Janzen DL, et al. Lipoma and liposarcoma: evaluation using CT and MR imaging. AJR 1997;169:589-94.

12. Greenspan A. Radiologia ortopédica. $3^{\underline{a}}$ ed. Rio de Janeiro: Guanabara Koogan, 2001:547-9. 